\title{
Strong inbreeding depression and individually variable mating system in the narrow endemic Erodium cazorlanum (Geraniaceae)
}

\author{
Conchita Alonso" \& Marina García-Sevilla \\ Estación Biológica de Doñana, CSIC (EBD-CSIC), Avda. Américo Vespucio s/n, E-41092 Sevilla, Spain \\ conalo@ebd.csic.es
}

\begin{abstract}
Alonso, C. \& García-Sevilla, M. 2013. Strong inbreeding depression and individually variable mating system in the narrow endemic Erodium cazorlanum (Geraniaceae). Anales Jard. Bot. Madrid 70(1): 72-80.

Angiosperms evolved different systems to attract effective pollinators while reducing selfing in hermaphroditic flowers. Selfing ability can be advantageous when pollinators and/or mates are scarce, although inbreeding depression may largely reduce those advantages. Recent comparative analyses suggested endemic species tend to evolve self-compatibility but a better understanding of the associated reproductive and genetic tradeoffs is required. Experimental hand-pollinations under greenhouse conditions were conducted to investigate the selfing ability and estimate inbreeding depression up to the offspring' first reproductive event in Ero dium cazorlanum, a narrow endemic species restricted to dolomite outcrops in SE Spanish mountains. We found autonomous selfing ineffective. Further, when experimentally applied, pollen of the same flower produced significantly fewer fruits and seeds compared to geitonogamous and cross pollinations. The number of seeds per fruit was significantly higher after cross pollinations and strong inbreeding depression accumulated through the life-cycle. Interestingly, individual plants exhibited broad variation in selfing ability with six out of 14 individuals producing no seed after geitonogamy. Understanding the consequences of individual variation in self compatibility deserves further investigation in the field now that we know that strong inbreeding depression may limit recruitment of selfed progeny.
\end{abstract}

Keywords: endemism, geitonogamy, inbreeding depression, mating system, self compatibility, stigmatic pollen load.

\section{INTRODUCTION}

The hermaphrodite flowers, characteristic of many Angiosperms, facilitate the deposition and collection of pollen by pollinators in just one visit but they also open the possibility that self pollination eventually reduce the benefits of outcrossing. Understanding how the compromise between genetic and reproductive costs and benefits of selfing may have triggered diversity of plant reproductive strategies and likely species diversification in Angiosperms remains as one of the hot topics in plant evolutionary biology (de Jong \& Klinkhamer, 2005; Barrett, 2008 and references therein; Goldberg \& al., 2010). Research on plant mating system of hermaphroditic species during the last two decades has revealed that intermediate mixed mating systems prevail among animal pollinated species (reviewed in Goodwillie \& al., 2005),

\section{Resumen}

Alonso, C. \& García-Sevilla, M. 2013. Acusada depresión por endogamia y sistema reproductivo variable entre individuos en una especie endémica estricta, Erodium cazorlanum (Geraniaceae). Anales Jard. Bot. Madrid 70(1): 72-80 (en inglés)

Las Angiospermas han desarrollado diversos sistemas para atraer polinizadores eficientes y al mismo tiempo reducir la posibilidad de autopolinización asociada al hermafroditismo. La capacidad de autopolinización puede ser ventajosa en situaciones de escasez de polinizadores y/o individuos reproductores, beneficios que pueden reducirse ampliamente a causa de la depresión por endogamia. Análisis filogenéticos recientes indicaron que las especies endémicas tienden a presentar sistemas de autocompatibilidad, por tanto es preciso analizar en profundidad los costes y beneficios reproductivos y genéticos asociados a la autocompatibilidad en estas especies. Mediante polinizaciones manuales en condiciones de invernadero se estimaron la capacidad de polinización espontánea, el grado de autocompatibilidad y la magnitud de depresión por endogamia acumulada hasta el primer evento reproductor de la progenie en Erodium cazorlanum, una especie endémica estricta asociada a unos pocos afloramientos dolomíticos en las montañas del SE español. La especie no mostró autonomía en la formación de semillas. Además, el polen de la propia flor aplicado experimentalmente sobre el estigma generó significativamente menos frutos y semillas que el polen de otras flores de la misma planta o de plantas diferentes. El número de semillas por fruto fue significativamente mayor en las polinizaciones cruzadas y la magnitud de depresión por endogamia acumulada a lo largo del ciclo de vida resultó ser muy elevada. Cabe destacar también la amplia variabilidad obtenida en los niveles de autocompatibilidad de las plantas individuales, encontrando incluso que seis de los 14 individuos ensayados no produjeron ninguna semilla por geitonogamia. Investigar el potencial adaptativo de esta variabilidad individual en condiciones naturales resulta clave para entender la dinámica evolutiva de esta especie ahora que sabemos que la depresión por endogamia puede constreñir el reclutamiento de progenies generadas por polen propio.

Palabras clave: endemismo, geitonogamia, depresión por endogamia, sistema reproductivo, autocompatibilidad, carga polínica estigmática.

and intraspecific variation in realized mating system can be substantial depending on reproductive traits and ecological conditions (see e.g. Barrett, 2003; Barrett \& al., 2004) making it more a population trait than a species attribute, at least in some cases. In addition, species with well-characterized selfincompatibility (SI) systems such as those found in the Brassicaceae and Solanaceae present some ability to set seeds with self pollen in some populations (Good-Avila \& al., 2008, and references therein). In these pseudo self compatible (PSC) species SI operates as a quantitative, rather than a qualitative, trait due to the segregation of unlinked genes that modify the strength of SI (Good-Avila \& al., 2008). Whether such intermediate strategies are widespread, artefactual or evolutionary labile is under debate (see Raduski \& al., 2012 and references therein). In some cases, PSC could be an evolutionary stage in 
the path towards self-compatibility (Allen \& Hiscock, 2008) particularly favored when mates are limiting (Busch \& Schoen, 2008), for instance in small populations of endemic species (e.g., Byers, 1995).

Recent comparative analyses suggested that endemic species tend to evolve self-compatibility (SC) systems (Alonso $\&$ al., 2010) but PSC was not considered as a possible stage. Interestingly, PSC has been found in several endemic species (e.g., Byers, 1995; Bush, 2005; Glemin \& al., 2005, Ortiz \& al., 2006; Nielsen \& al., 2007; Weber \& Goodwillie, 2009; Crawford \& al., 2010; Narbona \& al., 2011) suggesting that endemics could be good species candidates for studying ongoing evolutionary changes in mating system. Endemic species frequently experience high pollen limitation in the characteristically diverse communities where they occur (Vamosi \& al., 2006; Alonso \& al., 2010). Evolution of SC when mating possibilities are limiting may be particularly beneficial because autonomous selfers are expected to benefit from reproductive assurance (Kalisz \& Vogler, 2003), and those selfing species that require some pollination vector may still alleviate pollen limitation (e.g., Weber \& Goodwillie, 2009). Detailed experimental studies to ascertain the potential mating system of endemic species could be thus essential for conservation purposes in some cases (e.g., Demauro, 1993) but also informative to unravel evolutionary changes in mating system (see e.g. Carrió \& al., 2009; Narbona \& al., 2011).

Inbreeding depression is the main genetic cost of selfing with consequences for plant fitness and population viability. The magnitude of inbreeding depression is frequently environment-dependent and prevalent under stress (reviewed in Cheptou \& Donohue, 2011). Its effects can be delayed until stages of plant reproduction subsequent to the production of seeds, particularly in perennials (e.g., Barrett, 2003; Medrano \& al., 2005; Angeloni \& al., 2011). Importantly, the magnitude of inbreeding depression can be reduced in the prezygotic phase with increased pollen competition in the stigma purging genetic load of self pollen, improving fitness of selfed progeny and consequently reducing the costs of inbreeding (Armbruster \& Rogers, 2004; Lankinen \& Armbruster, 2007). Thus, determining the effects of timing and load of self pollen deposited on the stigma will be critical aspects to understand mating system and its reproductive consequences (Lankinen \& Madjidian, 2011).

In this study, we tested for spontaneous selfing ability, individual variability in relative success of self and cross pollinations and inbreeding depression at successive reproductive phases in Erodium cazorlanum, a spring flowering species endemic to SE Spanish dolomitic soils, categorized as vulnerable by UICN (Blanca \& al., 2009). Preliminary evidence indicating reduced floral visitation rates and reproductive success in some populations (Alonso \& al., 2004) prompted the study of mating system and inbreeding depression as potential constraints for the species persistence. Greenhouse experiments allowing efficient exclusion of pollinators, reduction of environmental heterogeneity, enlarged floral sample sizes, and detailed floral manipulations become particularly valuable when practical, ethical and legal restrictions apply to rare species with remote populations and/or fragile habitats, despite there is not a neat conclusion regarding the expected differences in magnitude of inbreeding depression obtained under natural and greenhouse conditions (Mena-Ali \& al., 2008; Angeloni \& al., 2011). Experimental hand-pollinations under homogenous greenhouse conditions were conducted to examine the effects of both pollen quantity and origin by varying pollen-load size of self pollen, the identity of cross pollen donors, and the use of one or two pollen donors per flower. Treatment outcomes were evaluated from seed production up to the offspring's first reproductive event. The following questions were explicitly addressed: Does autonomous selfing occur in E. cazorlanum? Are autogamous, geitonogamous and cross pollinations equally successful in terms of seed production and further offspring developmental stages? Does pollen load size or between sires competition affect pollination success? Do individual plants vary in the relative success of self and cross pollinations?

\section{MATERIAL AND METHODS}

\section{Study species}

Erodium cazorlanum Heywood (Geraniaceae) is a woody rosulate chamaephyte, octoploid and endemic to a few adjacent mountain ranges in southeastern Spain (Blanca \& al., 2009). Currently, it is mainly restricted to isolated dolomitic outcrops within the Natural Park of Sierras de Cazorla, Segura y Las Villas (Jaén province) where ca. 15 discrete, widely spaced populations are currently known. Flowers are hermaphrodite, pentamerous, last for 2-3 days, and are markedly protandrous. During floral development anthers draw back before stigma becomes receptive the following day, keeping them far away from stigmatic lobes, occasionally becoming detached from the filament and falling down, and, thus, functionally reducing the possibility of autonomous selfing (Fig. 1). Each anther produces 150-680 red pollen grains $(\mathrm{N}=10$ anthers each one from a different individual). During both male and female phases flowers produce small amounts of nectar in the base of each petal.

On average, individual plants produce 23 flowers per season (range 1-60 flowers; $\mathrm{N}=30$ plants). Flowers are clumped in pedunculate inflorescences steadily produced along the flowering season. Usually $\leq 5$ flowers are open per individual at a given date, frequently exhibiting asynchronous dichogamy (Fig. 1; C.A. unpubl. data). Flowering season starts early in the spring extending from late April to mid June, although a second flowering peak can occur in early autumn, and plants under greenhouse conditions remain flowering until the end of September. Fruits are schizocarps, each comprising five one-seeded mericarps.

The study was conducted on 14 adult E. cazorlanum potted plants provided by the Torre del Vinagre Botanical Garden in the Natural Park of Sierras de Cazorla, Segura y Las Villas, grown there from bulk seeds collected from a single population (Puerto del Tejo).

\section{Greenhouse experimentalpollinations}

During 2005, plants were kept under greenhouse conditions, watered daily and excluded from eventual pollinators with fine nylon tulle from the onset of flowering to midsummer when fruits were collected. Pollen was applied by cutting 


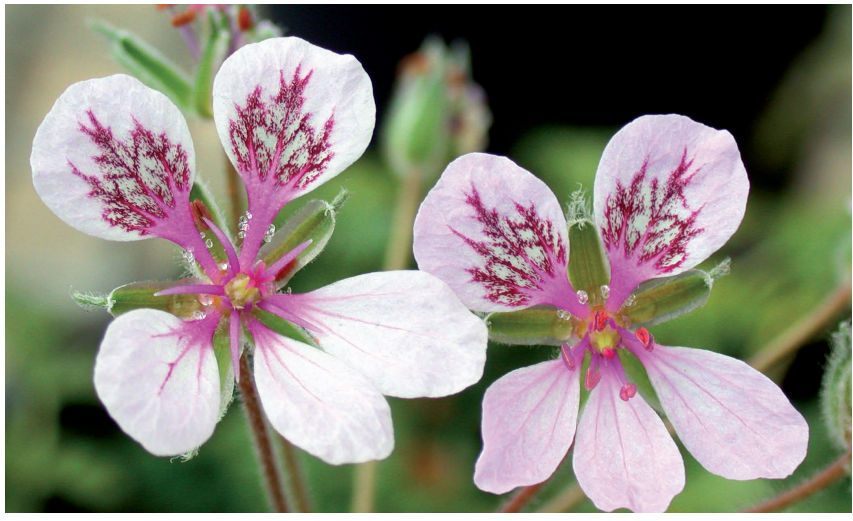

Fig. 1. Close view of two flowers of Erodium cazorlanum from the same inflorescence illustrating the morphological changes associated to floral ontogeny and protandry. Initially, during male phase (right flower) stigmatic lobes are closed, stamens are straight and anthers dehisce to offer pollen, note the two already dehisced anthers showing abundant red pollen. After, during female phase (left flower) the five receptive stigmatic lobes open in a star like shape, the stamens draw back and eventually anthers fall down, note that only one anther remains attached to the filament. Those changes functionally reduce the possibility of autonomous selfing but asynchrony among flowers allows geitonogamy.

a stamen with forceps and brushing the dehisced anther directly onto the stigma until all five lobes were thoroughly coated with pollen, as easily observed with magnifying glasses. In the vast majority of cases anthers were detached from the flower immediately before being used for experimental pollinations, only occasionally some anthers were preserved sealed in a vial till the next day if the recipient flower was not receptive. All pollinations were marked by placing a small numbered jeweler tag around the pedicel.

Fruit and seed production was quantified in enclosed and unmanipulated flowers to test for spontaneous selfing autonomy. The output of autogamous and geitonogamous handpollinations was compared by including a selfing pollination treatment with pollen from the same flower, conducted only when anthers did not fall down before the stigma became receptive, a treatment that was not feasible under field conditions because marked protandry and pollen depletion. Further, two levels of self pollen from a different flower were applied by brushing the stigma with one anther (low quantity) or two anthers (high quantity) to investigate the effect of increased stigmatic self pollen loads on the probability of setting fruit, the number of seeds/fruit or seed mass.

Crossings were conducted using pollen loads varying in quantity and quality by applying pollen from a single pollen donor or two in order to detect the effects of increased cross pollen competition on the probability of setting fruit, the number of seeds/fruit or seed mass. We allocated available receptive flowers to pollination treatments and sires as evenly as possible. Due to variation in floral display size and timing, the number of pollen recipient flowers per plant ranged 20-80, with an average of 46 recipient flowers per plant. Special care was taken to conduct self and cross treatments on similar dates in each plant to control for potential seasonal effects. Altogether we pollinated 630 flowers, 150 with self pollen (autogamy and geitonogamy), 221 with one sire cross pollen and 259 with two sires cross pollen. The pursued diallel crossing scheme in which all plants were used as both pollen donors and recipients was accomplished in a subset of eight plants for which we were able to further test for siring differences between individuals and the existence of reciprocal incompatibilities.

Developing fruits were individually covered with transparent food cellophane bags to collect seeds, accidentally some of the bags were open before collection and incomplete seed counts $(N=42)$ were excluded from seed set analyses. All seeds obtained $(\mathrm{N}=453)$ were individually weighed and seed mass was analyzed as an a priori surrogate of seed quality. Seeds obtained from selfing and one sire crossings $(\mathrm{N}=220)$ whose father was known with certainty were sown in September. Nine came from within-flower pollinations, 52 from within-plant pollinations and 159 from one sire cross pollinations. Germination trial of the 233 seeds obtained from the two sire treatment was discarded because the father was uncertain. Germination rates and survival under greenhouse conditions till the end of their first flowering event was recorded. Inbreeding depression coefficient $(\delta)$ was calculated for each life stage as $\delta=1-\left(\mathrm{w}_{\mathrm{s}} / \mathrm{w}_{\mathrm{x}}\right)$, where $\mathrm{w}_{\mathrm{s}}$ and $\mathrm{w}_{\mathrm{x}}$ are the fitness of selfed and crossed progeny, respectively. Fitness estimates per stage were sequentially multiplied to obtain a final multi-stage estimate of inbreeding depression. Flower production, spontaneous fruiting and survival after reproduction of the first generation offspring were also recorded.

\section{Statistical analyses}

All statistical analyses were conducted with SAS 9.2 (SAS Institute, 2008). The effects of pollination treatments were analyzed with Generalized Linear Mixed Models (Proc GLIMMIX) and the back transformed least squares adjusted means ( \pm s.e.), that estimate the marginal means corresponding to the fixed effects over a balanced population, will be presented. In this greenhouse study, pollination treatment and mother plant were considered as fixed effects while the sire effect was considered random because unbalanced sample size, except for the diallel analyses (see below). The effects of treatment were evaluated using the following planned contrasts: within-flower autogamous vs. within-plant geitonogamous selfing (with two levels); low vs. high quantity of within-plant selfing; one sire vs. two sires cross pollination; and within-plant geitonogamy (with two levels) vs. cross pollination (with two levels). Fruit set (proportion of treated flowers that eventually produced a fruit) and seed set per fruit (number of seeds out of five produced per fruit) were modeled as binomial processes using logits, seed mass was averaged per fruit and modeled with a normal distribution. The relationships between seed mass and the number of seeds per fruit and between seed mass and germination outcome were also explored. In addition, we calculated for each mother plant a continuous index of self-incompatibility (ISI) as the ratio of fruit set following geitonogamous self pollination compared to outcross pollination. Also, the number of selfed seeds per ovule divided by the number of outcrossed seeds per ovule was calculated for every mother plant, with values $<0.2$ being considered as evidence of self-incompatibility (Zapata \& Arroyo, 1978) and its relationship with the total number of flowers produced per plant analyzed. 
Differences in successive fitness components were estimated by assessing the treatments effect on seed germination and seedling survival till flowering, both modeled as binomial processes, including the original pollination treatment (self $v s$. cross) as a fixed effect whereas mother-plant effects were modeled as random because largely unbalanced sample sizes. Finally, differences in flower production by first-generation individuals were analyzed with pollination treatment provenance (self $v s$. cross) included as a fixed effect, mother-plant as random effect and the response variable modeled as negative binomial to improve model fit.

For the subset of eight plants involved in the diallel crossing scheme, siring differences between individuals were tested by introducing the identity of the single donor cross pollinations as a fixed effect modeling all other items as explained above.

\section{RESULTS}

\section{Selfing autonomy and relative success of autogamous and geitonogamous hand-pollinations}

Autonomous selfing was exceptional or accidental under greenhouse conditions and did not occur in all experimental plants. In total, 42 spontaneous fruits were developed out of $>3000$ unmanipulated flowers checked, and from those only four included a single full grown seed that did not germinate.

Accounting for the effects of individual variation (see below), within-flower hand-pollinations were on average less successful than geitonogamous hand-pollinations (Fig. 2A) and the probabilities of setting fruit under the two types of selfing treatments differed significantly $\left(F_{1,268}=11.21, P=\right.$ $0.0009)$. Seed-set per fruit was in contrast similar between the two types of selfing $\left(F_{1,231}=0.30, P=0.58\right.$; Fig. $\left.2 \mathrm{~B}\right)$ and selfed fruits set on average 1.1 seeds. We found that a high percentage of fruits had no full-grown seed inside, $40 \%$ in withinflower and $32.5 \%$ in within-plant treatments, respectively. The average number of seeds per fruit in selfed fruits as a group rose up to 1.64 after discarding fruits without seeds and still seed set per fruit was similar between the withinflower and within-plant selfing treatments $\left(F_{1,160}=0.001, P=\right.$ 0.96). Altogether, only $2.1 \%$ of the treated ovules set seeds after within-flower hand pollinations and $7.2 \%$ after withinplant hand pollinations $\left(F_{1,558}=12.21, P=0.0005\right)$.

\section{Early inbreeding depression: reproductive output after geitonogamy and outcrossing}

The quantity of self pollen applied did not affect either fruit set $\left(F_{1,268}=0.36, P=0.55\right.$; Fig. $\left.2 \mathrm{~A}\right)$ or seed set per fruit $\left(F_{1,231}=0.07, P=0.80 ;\right.$ Fig. $\left.2 \mathrm{~B}\right)$. We neither found differences between one and two sires cross treatments in terms of fruit set $\left(F_{1,268}=0.23, P=0.63\right.$; Fig. $\left.2 \mathrm{~A}\right)$ and seed set probabilities $\left(F_{1,231}=0.02, P=0.90\right.$; Fig. $\left.2 \mathrm{~B}\right)$, suggesting that pollen competition between individuals at the doses assayed did not quantitatively affect seed output.

Probability of setting a fruit with pollen from a different flower of either the same or another individual was similar and relatively low for hand-pollinations under greenhouse conditions (Table 1). The number of seeds per fruit was significantly higher after cross than self pollinations (Table 1).
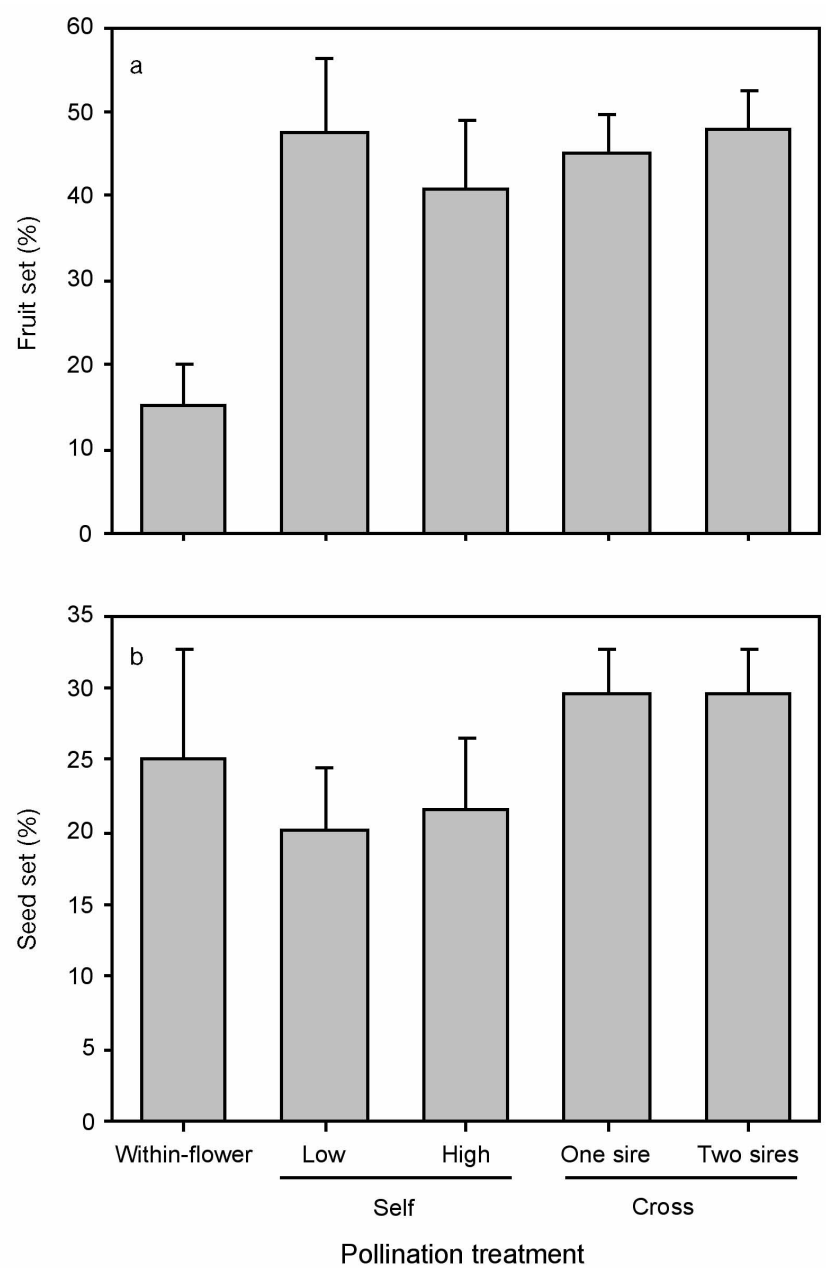

Fig. 2. Probability (least square means $+\mathrm{SE}$ ), after accounting for maternal fixed effects and siring random effects, that a treated Erodium cazorlanum flower eventually produce a fruit (a) and that each of the five ovules of a fruit give rise a full grown seed (b) following different hand pollination treatments under greenhouse conditions. Treatments included pollen from the same flower; two levels of self pollen from a different flower applied by brushing the stigma with one anther (low quantity) or two anthers (high quantity); and two types of cross pollen applied by brushing the stigma with one anther of a single donor (one sire) or two donors (two sires).

Discarding the fruits without full-grown seeds $32.5 \%$ and $25.9 \%$ of selfed and crossed fruits, respectively) the number of seeds per fruit remained higher after cross hand pollinations $\left(F_{1,160}=3.72, P=0.056\right)$. These results indicate that in $E$. cazorlanum inbreeding depression would primarily affect reproductive output throughout deleterious effects on the number of seeds per fruit. When both parameters were combined to estimate the proportion of treated ovules that eventually produce a seed after different pollination treatments we found that cross pollinations were significantly more successful (Table 1).

\section{Individual variation in success of hand-pollinations and self-compatibility index}

Differences among individuals in fruit set were highly statistically significant controlling for among-treatment differences $\left(F_{13,268}=5.97, P<0.0001\right)$. Different study plants set 
Table 1. Estimated fitness components of Erodium cazorlanum after within-plant self (geitonogamy) and cross pollinations conducted in 14 potted plants under greenhouse conditions. Self pollen comprised low and high quantity within-plant pollination treatments ( $\mathrm{N}=97$ flowers); cross pollen comprised one sire and two sires pollination treatments for the first four components ( $\mathrm{N}=480$ flowers), and only one sire treatment ( $\mathrm{N}=221 \mathrm{flowers}$ ) from the germination rates onwards. The significance of differences between the two pollen sources was tested throughout pre-planned contrast with Generalized Linear Mixed Models and thus numerator degrees of freedom was always 1 . Models included mother and sire as fixed and random effects, respectively (see methods for further details). Least square means \pm SE are shown. Inbreeding depression coefficient ( $\delta$ ) of quantitative fitness components is also shown. Seed mass was averaged per fruit before analyses.

\begin{tabular}{|c|c|c|c|c|c|c|}
\hline \multirow{2}{*}{ Fitness component } & \multicolumn{2}{|c|}{ Pollen source } & \multicolumn{3}{|c|}{ Statistics } & \multirow{2}{*}{$\delta$} \\
\hline & Geitonogamy & Cross & $F$ & ddf & $P$ & \\
\hline Fruits/flower (\%) & $43.9 \pm 6.2$ & $46.4 \pm 3.6$ & 0.14 & 268 & 0.71 & \\
\hline Seeds/fruit ${ }^{\mathrm{a}}(\%)$ & $20.8 \pm 3.6$ & $29.5 \pm 2.6$ & 5.09 & 231 & 0.025 & \\
\hline Seed $\operatorname{set}^{\mathrm{b}}(\%)$ & $7.2 \pm 1.2$ & $10.7 \pm 1.0$ & 8.18 & 558 & 0.004 & 0.33 \\
\hline Seed mass ${ }^{c}(\mathrm{mg})$ & $4.22 \pm 0.23$ & $5.08 \pm 0.13$ & 16.31 & 176 & $<0.0001$ & \\
\hline Germination (\%) & $16.8 \pm 6.3$ & $30.7 \pm 6.5$ & 3.94 & 11 & 0.07 & 0.45 \\
\hline Survival till $1^{\text {st }}$ flowering (\%) & $33.8 \pm 14.9$ & $62.0 \pm 7.4$ & 2.87 & 3 & 0.19 & 0.46 \\
\hline Survival post-flowering (\%) & $28.5 \pm 25.2$ & $47.5 \pm 10.8$ & 0.43 & 2 & 0.58 & 0.40 \\
\hline Offspring flower production & $116.5 \pm 29.0$ & $267.9 \pm 22.0$ & 10.08 & 38 & 0.003 & \\
\hline
\end{tabular}

a Percentage of the five ovules developed into seeds within a fruit. ${ }^{b}$ Percentage of total treated ovules developed into seeds. ${ }^{c}$ Not included to estimate the acumulative inbreeding coefficient.

$4.1 \%$ to $97.9 \%$ of treated flowers. Differences among individuals in seed set per fruit were also highly statistically significant $\left(F_{13,231}=9.30, P<0.0001\right)$ with different study plants filling their fruits with between $11.5 \%$ to $50.1 \%$ of the five available ovules per fruit. Consequently, the probability of setting a seed per ovule varied widely among mother plants $\left(F_{13,558}=13.45, P<0.0001 ;\right.$ Fig. $\left.3 \mathrm{~A}\right)$, thus indicating that plant individual features were highly influential for reproductive output after hand-pollinations under greenhouse conditions. No significant correlation was found across plants between average maternal seed set per ovule and flower production $\left(r_{s}\right.$ $=-0.05, \mathrm{~N}=14, P=0.87)$, a potential surrogate of individual condition.

Furthermore, the self incompatibility ratio index (ISI) based on seeds per ovule averaged 0.59 , supporting self compatibility at the species level, but also highlighting outstanding individual variation in self compatibility (Fig. 3B). Six individuals produced no seed after selfing, in contrast, four individuals exhibited higher success after selfing, and the other four presented intermediate values suggesting a PSC system. The individual ISI was neither significantly correlated to individual flower production $\left(\mathrm{N}=14, r_{s}=-0.14, P>0.40\right)$. Indeed, discarding the six self-incompatible mothers we found a higher fruit-set after selfing $(73.9 \% \pm 7.0$ vs. $53.0 \% \pm 4.9$; $\left.F_{1,138}=6.16, P=0.014\right)$, with a marginally significant lower proportion of seeds per fruit $(32.6 \% \pm 4.7$ vs. $42.4 \% \pm 3.1$; $\left.F_{1,109}=3.43, P=0.067\right)$ that led to absence of differences between treatments in the proportion of seeds per ovule produced $\left(13.5 \% \pm 1.7\right.$ vs. $\left.13.9 \% \pm 2.7 ; F_{1,318}=0.02, P=0.89\right)$ and, thus, absence of inbreeding depression in terms of seed output of self-compatible mothers.

The diallel design revealed significant differences between individuals in their seed siring success $\left(F_{7,62}=2.64, P=0.019\right)$ that ranged between 9 and $34 \%$ seeds of the attempted ovules and was unrelated to their maternal ability to produce seeds after cross pollinations $\left(r_{s}=-0.024, \mathrm{~N}=8, P=0.95\right.$; for the diallel design). We did not find evidence of reciprocal incompatibilities among the eight individuals assayed.

\section{Late inbreeding depression: seed mass, germination, seedling survival and next-generation reproduction}

Seeds that germinated were only marginally heavier than those that failed to do it under greenhouse conditions $(5.19 \pm$ $0.18 \mathrm{mg}$ vs. $4.89 \pm 0.13 \mathrm{mg}$, respectively; $F_{1,205}=3.38, P=$ 0.068). Once more, differences among mother plants were highly statistically significant in determining seed mass $\left(F_{13,205}\right.$ $=11.88, P<0.0001)$. However, in the diallel design sires were not found to differ in the average mass of sired seeds $\left(F_{7,18}=\right.$ $0.45, P=0.85$ ).

As regards the effects of pollination treatments on per fruit averaged seed mass, we found that seed mass was similar between the two within-plant self pollination treatments $(4.08 \pm$ $0.30 \mathrm{mg}$ vs. $4.35 \pm 0.27 \mathrm{mg}$ for low and high quantity of self pollen, respectively; $F_{1,176}=0.53, P=0.47$ ) and also between the one and two sires cross treatments $(5.02 \pm 0.15 \mathrm{mg}$ vs. 5.17 $\pm 0.15 \mathrm{mg}$, respectively; $\left.F_{1,176}=0.92, P=0.34\right)$. In contrast, seeds were significantly heavier after cross than within-plant self pollinations (Table 1) suggesting that inbreeding depression affects seed provisioning in E. cazorlanum. Curiously, seeds produced by within-flower pollinations were slightly but non-significantly heavier than those obtained by withinplant pollinations $\left(4.96 \pm 0.42 \mathrm{mg}\right.$ vs. $4.22 \pm 0.23 \mathrm{mg} ; F_{1,176}=$ 2.81, $P=0.096)$

Germination rates were globally low. Seeds obtained from cross pollinations were marginally more successful than those obtained from within-plant self pollinations (Table 1), whereas percentage of germination was similar between selfing treatments $\left(13.9 \pm 13.4 \%\right.$ for within-flower pollinations; $F_{1,11}=$ $0.04, P=0.85)$. None of the seedlings originated from withinflower pollinations survived till flowering. Survival rates were higher for crossed than selfed seedlings although such differences were not statistically significant after accounting for random among-plant variation effect (Table 1). Inbreeding depression coefficient from germination till flowering stage was 0.70 . Furthermore, floral production was significantly higher in crossed than in selfed seedlings (Table 1). Finally, after flowering only 17 out of 40 individuals survived, survival 
rates were again higher for crossed than selfed individuals, although such differences were not statistically significant after accounting for random among-plant variation effect (Table 1).

To sum up, inbreeding depression was cumulatively strong in E. cazorlanum under greenhouse conditions. Self pollen was unable to produce seeds in some individuals and also cross pollinations resulted in a higher number of seeds per fruit. Further, we found a qualitative effect on seed provisioning and germination ability, seedling survival till the first reproductive event, first generation floral display size and further survival. Altogether only one of the survivors after the first flowering event was originated from the 750 self pollinated ovules whereas 16 came from the 1105 ovules treated with cross pollen from a single donor.

\section{DISCUSSION}

Inbreeding depression is a strong evolutionary force able to modulate changes in Angiosperms mating system to effectively attract pollinators while reduce selfing (Barrett, 2003). In the following paragraphs we discuss the implications that high inbreeding depression may have in the evolution of mating system and population persistence of a non-autonomous habitat specialist endemic species.

\section{Pollen vector requirement and individual variation in experimental self compatibility}

In this study, we found that unpollinated flowers of E. cazorlanum may occasionally start swelling the fruit but very rarely produce some seeds. Marked protandry and changes in the relative location of anthers and stigma promoting herkogamy during floral ontogeny combined to highly limit the ability for autonomous selfing in E. cazorlanum. Nonetheless, the species was able to produce seeds when pollen from the same flower was experimentally applied onto the stigma, although this treatment was quantitatively less successful than within plant geitonogamous pollinations supporting an adaptive value of avoiding autonomous selfing (Fig. 1). The reduced ability of the pollen of the same flower to produce fruits and seeds might be partially related to a decrease of pollen fertilization ability with aging associated to delayed female phase within the flower (Dafni \& Firmage, 2000), that was not fully overcome by our experimental procedure. The potential advantage of stamens movement for increasing pollen export during the male phase should be tested under a natural pollination regime (see e.g. Sun \& al., 2011 for flexistyly).

As regards selfing after geitonogamy, the amount of pollen applied did not quantitatively affect reproductive output, suggesting that both treatments exceeded the pollen load threshold for quantity limitation of seed production (Aizen \& Harder, 2007; Alonso \& al., 2012). Similarly, increased pollen load size aiming to enhance pollen competition did not influence seed mass or germination as expected from added options for purging the genetic load of self pollen (Armbruster \& Rogers, 2004; Lankinen \& Armbruster, 2007), perhaps because even the low quantity treatment supplied enough pollen for strong pollen competition (Marshall \& al., 2007). Still we cannot disregard the possibility that differences be-
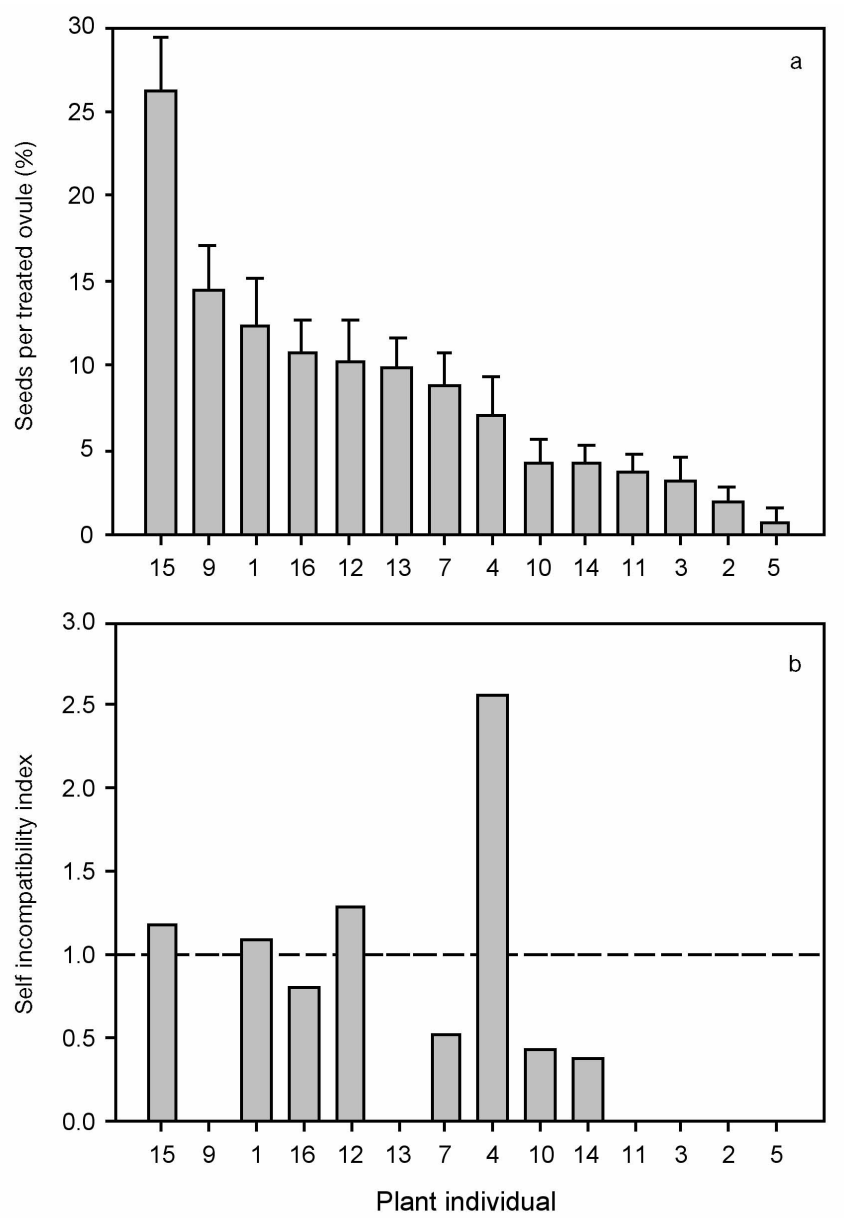

Fig. 3. a, differences among mother plants in the probability (least square mean + SE) that a treated ovule eventually produce a seed, after accounting for the fixed effects of pollination treatments applied and siring random effects. $\mathbf{b}$, individual self incompatibility index calculated as the ratio between the percentage of seeds per ovule obtained following self and cross pollinations, respectively. The dashed line indicates the same ability to produce seeds after self and cross pollinations and cero values applied to individuals unable to produce seeds after self pollinations.

tween the amount of pollen receipt could appear at lower doses as those expected to received from insect pollinators, later reproductive stages or under natural conditions (see e.g., Kalla \& Ashman, 2002). In addition, we found that many fruits did not fully develop any seed, a feature in common with other Erodium (Albert \& al., 2001) and Geranium species (Hessing, 1989). Consequently, success in setting seeds was remarkably lower than for setting fruits $(<11 \%$ vs. $>43$ $\%$ for seed and fruit set respectively), an aspect to consider when comparing fruit set values (see also Raduski \& al., 2012), and also relatively low for experimental hand pollinations in potted plants. Geitonogamous self pollinations were found to be quantitatively less successful than cross pollinations in terms of seeds per fruit and seed set, although the relative success of both treatments (ISI $=0.59$ ) would still classify E. cazorlanum as a SC species according to the widely accepted criterion of ISI $\geq 0.2$ (Igic \& al., 2008; Raduski \& al., 2012).

An unanticipated result of this greenhouse study was that individual plants exhibited broad variation in selfing ability 
(Fig. 2), an aspect that has been rarely reported in the literature but seems to be not such an uncommon phenomenon (see Raduski \& al., 2012). Six out of 14 individuals produced no seed after experimental geitonogamy, and one exhibited much higher success after self than cross pollinations. Whether this fact would be adaptive or not is controversial because in non autonomous SC species mating system will largely depend on pollinators behavior and, thus, could be non adaptive (Kalisz \& Vogler, 2003). However, maternal differences in self compatibility with a genetic basis could be under natural selection (Levin, 1996; Good-Avila \& Stephenson, 2003). There are SI species in Geraniaceae (de Nettancourt, 1997), even individual variation in self compatibility has been reported in the family (Hessing, 1989, and references therein), but we are not aware of any study describing the genetic basis underlying such phenomenon. Further, based on floral design it has been suggested that different mating strategies exist in Erodium sp. with E. cazorlanum having recently evolved within the most variable clade (Alarcón \& al., 2011). Noteworthy, ploidy levels are variable within the Erodium genus, with some species closely related to E. cazorlanum being variable at the intraspecific level (Alarcón \& al., 2011). Complex relationships exist between polyploidy, mating system and inbreeding depression that would be worth to empirically asses within variable lineages and species to further clarify the evolutionary processes linking to each other (Barringer, 2007).

As regards reproductive success, this greenhouse study revealed that individual seed production can be affected by the relative amount of self and cross pollen deposited on the stigmas by pollinators, making E. cazorlanum a species susceptible of being qualitatively pollen limited (Aizen \& Harder, 2007; Alonso \& al., 2010). Under natural conditions usually not more than five flowers per plant are open simultaneously and, thus, we expect a mixed mating system largely dependent on flower production, synchrony among flowers and pollinators abundance and behavior (e.g. Albert \& al., 2008; Karron \& al., 2009). Thus, consequences of individual variation in SC in E. cazorlanum deserve further study in natural populations. In this context, it is important to recall that both resources and pollen can limit plant reproduction (Burd, 2008). In the field, E. cazorlanum individual plants produce a number of flowers that ranges from 1 to 60 depending on plant size and season whereas individuals in the greenhouse were able to extend their flowering season and produce more than 400 flowers. Such dramatic differences suggest that plant reproduction is likely to be limited by the harsh environmental conditions typical of dolomite soils (Mota \& al., 2008) and unpredictable spring precipitation of Western Mediterranean mountains (Romero \& al., 1998; Romero \& al., 1999). Thus, the relative role of resource and pollen limitation of seed production should be further examined in the field (e.g., Asikainen \& Mutikainen, 2005).

\section{Inbreeding depression and evolution of mating system in a narrowly distributed species}

Although a recent meta-analysis link the magnitude of inbreeding depression more to plant population size than to species specific traits (Angeloni \& al., 2011), previous studies suggested that species that typically outcross tend to have greater inbreeding depression than species that typically self (Husband \& Schemske, 1996), and that inbreeding depression is usually greater when measured under field than under greenhouse (benign) conditions (Mena-Ali \& al., 2008 and references therein; but see Angeloni \& al., 2011). The magnitude of inbreeding depression also varied among different life-cycle stages (Angeloni \& al., 2011). For E. cazorlanum, we found that the quality of crossed seeds was consistently higher in terms of mass, germination, survival and flower production (Table 1) indicating a strong inbreeding depression even under the relatively benign greenhouse conditions, with a cumulative coefficient encompassing the whole life cycle from seed production to offspring survival after the first reproductive event $\delta=0.78$. This figure is at the higher boundary even for SI species (Husband \& Schemske, 1996), thus, suggesting a long prior history of reduced selfing. Such strong inbreeding depression will condition individual fitness, and population demography would be indeed much largely affected by pollen quality issues associated to pollinators behavior than expected from the seed output difference observed between experimental self and cross pollinations (see also Herrera, 2000).

Accordingly, E. cazorlanum mating system will determine seed output and the initial quality variation among siblings but inbreeding depression before the offspring reach reproductive stage will favor cross offspring establishment (Barrett, 2003; Medrano \& al., 2005; Robertson \& al., 2011) and, thus, maternal plants with reduced selfing, even if were able to produce less seeds, could get higher fitness in the long term and spread into the population. Additionally, the reduced reproductive output and germination rates here recorded could be associated to genetic load, owing to the reduced genetic variability and biparental inbreeding associated to small and spatially isolated populations (Richards, 2000). A partial self compatibility strategy may be particularly beneficial in small populations, unpredictable environments and during colonization processes (Levin, 1996), all features typical of marginal populations (e.g., Herlihy \& Eckbert, 2005), but occurring also in habitat specialists. When small, isolated or poor quality habitat patches lead to small populations with low genetic variation (reviewed in Cole, 2003; but see Medrano \& Herrera, 2008) and mates become limiting, SC individuals would be favored (Busch \& Schoen, 2008). Alternatively, seed discounting and strong inbreeding depression will largely increase the relative fitness of SI individuals under resource limitation of seed production, expected to arise in poor dolomitic soils with unpredictable rainy seasons where $E$. cazorlanum populations occur (see above). Thus, if mating and resource limitations are variable among sites, years or both, partial self compatibility could be an evolutionary stable reproductive strategy (Harder \& al., 2008).

Population and individually variable self-compatibility has been found in several endemic species as mentioned at Introduction. Such variable species can be good model systems to trace evolutionary pathways in mating systems also at intraspecific levels (e.g., Koelling \& al., 2011). Classical greenhouse experiments become excellent for the detailed studies 
of mating system and inbreeding depression at successive reproductive stages required to initially understand the potential advantages and disadvantages of selfing in these species whose extensive manipulation in the field may be problematic. From a conservation viewpoint, threats to narrow endemic species could arise from their genetic background (Ellstrand \& Ellam, 1993; Angeloni \& al., 2011), limited reproduction at biodiversity hotspots (Alonso \& al., 2010) or a combination of both factors throughout transitions in mating system than could alleviate some of the risks. Further field studies relating population size, realized mating system and quantity and quality limitation of seed production are required to understand relevance of mating system for population structure and conservation of endemic species.

\section{ACKNOWLEDGEMENTS}

We thank the staff at Jardín Botánico Torre del Vinagre and Viveros de San Jerónimo (Junta de Andalucía) for technical assistance during the study, C.M. Herrera for continuous inspiring discussion and providing the picture included in the paper, M. Ferrer Ortega, M. Medrano and two anonymous referees for reviewing earlier versions of the manuscript, and A.R. Castilla for providing some very useful literature. The study was funded by the Spanish Ministerio de Educación y Ciencia through research project CGL 200601355/BOS, and FBBVA through the research project ENDLIMIT (BIOCON08/125).

\section{REFERENCES}

Aizen, M.A. \& Harder, L.D. 2007. Expanding the limits of the pollen-limitation concept: effects of pollen quantity and quality. Ecology 88: 271-281.

Alarcón, M.L., Roquet, C. \& Aldasoro, J.J. 2011. Evolution of pollen/ovule ratios and breeding system in Erodium (Geraniaceae). Systematic Botany 36: 661-676.

Albert, M.J., Escudero, A. \& Iriondo, J.M. 2001. Female reproductive success of narrow endemic Erodium paularense in contrasting microhabitats. Ecology 82: 1734-1747.

Albert, M.J., Iriondo, J.M., Escudero, A. \& Torres, E. 2008. Dissecting components of flowering pattern: size effects on female fitness. Botanical Journal of the Linnean Society 156: 227-236.

Allen, A.M. \& Hiscock, S.J. 2008. Evolution and phylogeny of self-incompatibility systems in Angiosperms. In: V.E. Franklin-Tong (ed.), Self-incompatibility in flowering plants. Evolution, diversity, and mechanisms: 73-101. Berlin, Springer-Verlag.

Alonso, C., Garrido, J.L. \& Herrera, C.M. 2004. Investigaciones sobre plantas y animales en las Sierras de Cazorla, Segura y Las Villas. 25 años de estudios por el CSIC. Sevilla, Consejería de Medio Ambiente, Junta de Andalucía.

Alonso, C., Herrera, C.M. \& Ashman, T.L. 2012. A piece of the puzzle: a method for comparing pollination quality and quantity across multiple species and reproductive events. New Phytologist 193: 532-542.

Alonso, C., Vamosi, J.C., Knight, T.M., Steets, J.A. \& Ashman, T.-L. 2010. Is reproduction of endemic plant species particularly pollen limited in biodiversity hotspots? Oikos 119: 1192-1200.

Angeloni, F., Ouborg, N.J. \& Leimu, R. 2011. Meta-analysis on the association of population size and life history with inbreeding depression in plants. Biological Conservation 144: 35-43.

Armbruster, W.S. \& Rogers, D.G. 2004. Does pollen competition reduce the cost of inbreeding? American Journal of Botany 91: 1939-1943.

Asikainen, E. \& Mutikainen, P. 2005. Pollen and resource limitation in a gynodioecious species. American Journal of Botany 92: 487-494.

Barrett, S.C.H. 2003. Mating strategies in flowering plants: the outcrossing selfing paradigm and beyond. Philosophical transactions of the Royal Society of London. Series B, Biological sciences 358: 991-1004.

Barrett, S.C.H. 2008. Major evolutionary transitions in flowering plant reproduction: an overview. International Journal of Plant Sciences 169: 1-5.

Barrett, S.C.H., Cole, W.W. \& Herrera, C.M. 2004. Mating patterns and genetic diversity in the wild daffodil Narcissus longispathus (Amaryllidaceae). Heredity 92: 459-465.
Barringer, B.C. 2007. Polyploidy and self-fertilization in flowering plants. American Journal of Botany 94: 1527-1533.

Blanca, G., Cabezudo, B., Cueto, M., Fernández López, C. \& Morales Torres, C. 2009. Flora Vascular de Andalucía Oriental. Sevilla, Consejería de Medio Ambiente, Junta de Andalucía.

Burd, M. 2008. The Haig-Westoby model revisited. The American Naturalist 171: 400-404.

Busch, J.W. 2005. The evolution of self-compatibility in geographically peripheral populations of Leavenworthia alabamica (Brassicaceae). American Journal of Botany 92: 1503-1512.

Busch, J.W. \& Schoen, D. J. 2008. The evolution of self-incompatibility when mates are limiting. Trends in Plant Science 13: 128-136.

Byers, D.L. 1995. Pollen quantity and quality as explanations for low seed set in small populations exemplified by Eupatorium (Asteraceae ). American Journal of Botany 82: 1000-1006.

Carrió, E., Jiménez, J.F., Sánchez-Gómez, P. \& Güemes, J. 2009. Reproductive biology and conservation implications of three endangered snapdragon species (Antirrhinum, Plantaginaceae). Biological Conservation 142: 1854-1863.

Cheptou, P.-O. \& Donohue, K. 2011. Environment-dependent inbreeding depression: its ecological and evolutionary significance. New Phytologist 189: 395-407.

Cole, C.T. 2003. Genetic variation in rare and common plants. Annual Review of Ecology, Evolution and Systematics 34: 213-237.

Crawford, D.J., Archibald, J.K., Kelly, J.K., Mort, M.E. \& Santos-Guerra, A. 2010. Mixed mating in the 'obligately outcrossing' Tolpis (Asteraceae) of the Canary Islands. Plant Species Biology 25: 114-119.

Dafni, A. \& Firmage, D. 2000. Pollen viability and longevity: practical, ecological and evolutionary implications. Plant Systematics and Evolution 222: 113-132.

Demauro, M.M. 1993. Relationship of breeding system to rarity in the lakeside daisy (Hymenoxys acaulis var.glabra). Conservation Biology 7: 542 550.

Ellstrand, N.C. \& Elam, D.R. 1993. Population genetic consequences of small population size: implications for plant conservation. Annual Review of Ecology and Systematics 24: 217-242.

Glemin, S., Gaude, T., Guillemin, M.L., Lourmas, M., Olivieri, I. \& Mignot, A. 2005. Balancing selection in the wild: Testing population genetics theory of self-incompatibility in the rare species Brassica insularis. Genetics 171: 279-289

Goldberg, E.E., Kohn, J.R., Lande, R. \& Robertson, K.A. 2010. Species selection maintains self-incompatibility. Science 330: 493-495.

Good-Avila, S.V., Mena-Alí, J.I. \& Stephenson, A.G. 2008. Genetic and environmental causes and evolutionary consequences of variations in selffertility in self incompatible species. In: V.E. Franklin-Tong (ed.), Selfincompatibility in flowering plants. Evolution, diversity, and mechanisms: 33-52. Berlin, Springer-Verlag.

Good-Avila, S.V. \& Stephenson, A.G. 2003. Parental effects in a partially self-incompatible herb Campanula rapunculoides L. (Campanulaceae): influence of variation in the strength of self-incompatibility on seed set and progeny performance. The American Naturalist 161: 615-630.

Goodwillie, C., Kalisz, S. \& Eckert, C.G. 2005. The evolutionary enigma of mixed mating systems in plants: occurrence, theoretical explanations, and empirical evidence. Annual Review of Ecology, Evolution and Systematics 36: 47-79.

Harder, L.D., Richards, S.A. \& Routley, M.B. 2008. Effects of reproductive compensation, gamete discounting and reproductive assurance on mating-system diversity in hermaphrodites. Evolution 62: 157-172.

Herlihy, C.R. \& Eckert, C.G. 2005. Evolution of self-fertilization at geographical range margins? Comparison of demographic, floral, and mating system variables in central vs. peripheral populations of Aquilegia canadensis (Ranunculaceae). American Journal of Botany 92: 744-751.

Herrera, C.M. 2000. Flower-to-seedling consequences of different pollination regimes in an insect-pollinated shrub. Ecology 81: 15-29.

Herrera, C.M. \& Jovani, R. 2010. Lognormal distribution of individual lifetime fecundity: insights from a 23-year study. Ecology 91: 422-430.

Hessing, M.B. 1989. Variation in self-fertility and floral characters of Geranium-caespitosum (Geraniaceae) along an elevational gradient. Plant Systematics and Evolution 166: 225-241.

Husband, B.C. \& Schemske, D.W. 1996. Evolution of the magnitude and timing of inbreeding depression in plants. Evolution 50: 54-70. 
Igic, B., Lande, R. \& Kohn, J.R. 2008. Loss of self-incompatibility and its evolutionary consequences. International Journal of Plant Science 169: 93-104.

Jong, T.J. de \& Klinkhamer, P.G.L. 2005 Evolutionary ecology of plant reproductive strategies. Cambridge: Cambridge University Press.

Kalisz, S. \& Vogler, D.W. 2003. Benefits of Autonomous Selfing Under Unpredictable Pollinator Environments. Ecology 84: 2928-2942.

Kalla, S.E. \& Ashman, T.-L. 2002. The effects of pollen competition on progeny vigor in Fragaria virginiana (Rosaceae) depend on progeny growth environment. International Journal of Plant Sciences 163:335-340

Karron, J.D., Holmquist, K.G., Flanagan, R.J. \& Mitchell, R.J. 2009. Pollinator visitation patterns strongly influence among-flower variation in selfing rate. Annals of Botany 103: 1379-1383.

Koelling, V., Hamrick, J. \& Mauricio, R. 2011. Genetic diversity and structure in two species of Leavenworthia with self-incompatible and self-compatible populations. Heredity 106: 310-318.

Lankinen, A. \& Armbruster, W.S. 2007. Pollen competition reduces inbreeding depression in Collinsia beterophylla (Plantaginaceae). Journal of Evolutionary Biology 20: 737-749.

Lankinen, A. \& Madjidian, J.A. 2011. Enhancing pollen competition by delaying stigma receptivity: pollen deposition schedules affect siring ability, paternal diversity, and seed production in Collinsia heterophylla (Plantaginaceae). American Journal of Botany 98: 1191-1200.

Lavergne, S., Thompson, J.D., Garnier, E. \& Debussche, M. 2004. The biology and ecology of narrow endemic and widespread plants: a comparative study of trait variation in 20 congeneric pairs. Oikos 107: 505-518.

Levin, D.A. 1996. The evolutionary significance of pseudo-self-fertility. The American Naturalist 148: 321-332.

Marshall, D.L., Shaner, M.G.M. \& Oliva, J.-P. 2007. Effects of pollen load size on seed paternity in wild radish: the roles of pollen competition and mate choice. Evolution 61: 1925-1937.

Medrano, M., Alonso, C. \& Herrera, C.M. 2005. Mating system, sex ratio, and persistence of females in the gynodioecious shrub Daphne laureola $\mathrm{L}$. (Thymelaeaceae). Heredity 94:37-43.

Medrano, M. \& Herrera, C.M. 2008. Geographical structuring of genetic diversity across the whole distribution range of Narcissus longispathus, a habitat-specialist, Mediterranean narrow endemic. Annals of Botany 102: 183-194.

Mena-Alí, J.I., Keser, L.H. \& Stephenson, A.G. 2008. Inbreeding depression in Solanum carolinense (Solanaceae), a species with a plastic self-incompatibility response. BMC Evolutionary Biology 8: 10.

Mota, J.F., Medina-Cazorla, J.M., Navarro, F.B., Pérez-García, F.J., PérezLatorre, A., Sánchez-Gómez, P., Torres, J.A., Benavente, A., Blanca, G., Gil, C., Lorite, J. \& Merlo, M.E. 2008. Dolomite flora of the Baetic Ranges glades (South Spain). Flora 203: 359-375.

Murray, B.R., Thrall, P.H., Gill, A.M. \& Nicotra, A. B. 2002. How plant lifehistory and ecological traits relate to species rarity and commonness at varying spatial scales. Austral Ecology 27: 291-310.

Narbona, E., Ortiz, P.L. \& Arista, M. 2011. Linking self-incompatibility, dichogamy, and flowering synchrony in two Euphorbia species: alternative mechanisms for avoiding self-fertilization? PlosOne 6: e20668. doi: 10.1371/journal.pone.0020668.

Nettancourt, D. de. 1977. Incompatibility in Angiosperms. Monographs on Theoretical and Applied Genetics. Berlin, Springer-Verlag.

Nielsen, L.R., Siegismund, H.R. \& Hansen, T. 2007. Inbreeding depression in the partially self-incompatible endemic plant species Scalesia affinis (Asteraceae) from Galápagos islands. Evolutionary Ecology 21: 1-12.

Ortiz, M.A., Talavera, S., García-Castaño, J. L., Tremetsberger, K., Stuessy, T., Balao, F. \& Casimiro-Soriguer, R. 2006. Self-incompatibility and floral parameters in Hypochaeris sect. Hypochaeris (Asteraceae). American Journal of Botany 93: 234-244.

Raduski, A.R., Haney, E.B. \& Igic, B. 2012. The expression of self-incompatibility in angiosperms is bimodal. Evolution 66: 1275-1283.

Richards, C. 2000. Inbreeding depression and genetic rescue in a plant metapopulation. The American Naturalist 155: 383-394.

Robertson, A.W., Kelly, D. \& Ladley, J.J. 2011. Futile selfing in the trees Fuchsia excorticata (Onagraceae) and Sophora microphylla (Fabaceae): inbreeding depression over 11 years. International Journal of Plant Science 172: $191-198$

Romero, R., Guijarro, J.A., Ramis, C. \& Alonso, S. 1998. A 30-year (19641993) daily rainfall data base for the Spanish Mediterranean regions: First exploratory study. Journal of Climatology 18: 541-560.

Romero, R., Ramis, C. \& Guijarro, J.A. 1999. Daily rainfall patterns in the Spanish Mediterranean area: an objective classification. International Journal of Climatology 112: 95-112.

SAS. 2008. SAS for Windows (version 9.2). Cary, North Carolina: SAS Institute.

Schlichting, C.D. \& Devlin, B. 1992. Pollen and ovule sources affect seed production of Lobelia cardinalis (Lobeliaceae). American Journal of Botany 79: 891-898.

Sun, S., Zhang, D.-Y., Ives, A.R. \& Li, Q.-J. 2011. Why do stigmas move in a flexistylous plant? Journal of Evolutionary Biology 24: 497-504.

Thompson, J.D., Lavergne, S., Affre, L., Gaudeul, M. \& Debussche, M. 2005. Ecological differentiation of Mediterranean endemic plants. Taxon 54: 967-976.

Vamosi, J.C., Knight, T.M., Steets, J.A., Mazer, S.J., Burd, M. \& Ashman, T.L. 2006. Pollination decays in biodiversity hotspots. Proceedings of the National Academy of Science 103: 956-961.

Weber, J.J. \& Goodwillie, C. 2009. Evolution of the mating system in a partially self-incompatible species: reproductive assurance and pollen limitation in populations that differ in the timing of self-compatibility. International Journal of Plant Sciences 170: 885-893.

Zapata, T.R. \& Arroyo, M.T.K. 1978. Plant reproductive ecology of a secondary deciduous tropical forest in Venezuela. Biotropica 10: 221-230.

Associate Editors: Javier Fuertes / Luis Navarro Received: 13-IX-2012 Accepted: 16-V-2013 